\title{
LA EFICIENCIA DINÁMICA EN LA ECONOMÍA DE UN CAMPO DE CONCENTRACIÓN NAZI
}

\author{
DAVID SANZ BAS*
}

Resumen: La actividad económica tiende a auto-organizarse en todas las situaciones imaginables gracias a la fuerza coordinadora y creativa de la función empresarial. Así, en los campos de prisioneros de guerra de la Segunda Guerra Mundial se formó de manera espontánea toda una economía de mercado impulsada por la empresarialidad basada en la moneda-cigarrillo y en el intercambio libre en la que los reclusos trataban de mejorar su bienestar material mediante la cooperación voluntaria. A través del testimonio de un economista que luchó en el ejército británico y que fue capturado por el ejército alemán podemos conocer con detalle cuál fue el proceso de desarrollo de esta economía tan peculiar. El presente trabajo pretende ser una interpretación austriaca del testimonio de R.A. Radford sobre el desarrollo de estos procesos haciendo hincapié en el papel protagonista de la empresarialidad y evaluando en todo momento el grado de eficiencia dinámica de los mismos.

Palabras clave: Función empresarial, eficiencia dinámica, campo de prisioneros, moneda cigarrillo.

Abstract: The economic activity tends to self-organize under every imaginable situation thanks to the coordinating and creative force of entrepreneurship. Thus, during the Second World War, a market economy developed spontaneously in P.O.W. camps, driven by the entrepreneurship based on the cigarette currency and on free exchange, in which prisoners

* Licenciado en Cc. Económicas por la Universidad Complutense de Madrid y miembro de Instituto Juan de Mariana. Agradezco los comentarios de todas las personas que me han ayudado a revisar este trabajo, en especial a Alejandro Sanz, Ana Bas y Mercedes Rodríguez. El autor agradece cualquier comentario sobre este trabajo a davidsanzbas10@gmail.com 
tried to improve their material welfare by means of voluntary cooperation. Through the testimony of an economist, who fought in the British army and who was captured by the German army, we get to know in detail the development process of this so odd economy. The present work aims at an Austrian interpretation of R.A. Radford's testimony about the development of these processes, putting special emphasis on the leading role of entrepreneurship and evaluating their dynamic efficiency degree at all times.

Key words: Entrepreneurship, dynamic efficiency, P.O.W. camp, cigarette currency.

«El arte del comerciante consiste en llevar una cosa desde el sitio donde abunda al lugar donde se paga cara»

Sir Laurence Olivier

\section{PROPÓSITO DEL TRABAJO}

Mi objetivo es analizar la eficiencia dinámica de los procesos sociales que surgieron de forma espontánea en los campos de prisioneros de guerra durante la Segunda Guerra Mundial; para ello me basaré en el testimonio que R. A. Radford nos dejó en su famoso artículo ${ }^{1}$ «The Economic Organization of a P.O.W. Camp».

Primero haré un breve comentario teórico sobre qué entienden por eficiencia económica los economistas neoclásicos y cuál es el concepto austriaco de eficiencia; acto seguido pasaré a analizar desde un punto de vista austriaco los procesos sociales que se dieron de forma espontánea en los campos de prisioneros de la Segunda Guerra Mundial. Finalmente habrá un apartado donde expondré brevemente mis conclusiones.

1 Radford, R.A., «The Economic Organization of a P.O.W. Camp», en Economica, Noviembre 1945, Vol. 12. pp. 189-201. 


\section{PRIMERA PARTE: \\ EL CONCEPTO DE EFICIENCIA ECONÓMICA}

En esta primera parte pretendo realizar una breve síntesis teórica sobre el concepto de eficiencia económica. Podemos decir que existen dos dimensiones de este concepto: la eficiencia estática y la eficiencia dinámica. Pasemos a explicarlas.

\section{La eficiencia estática}

En todos los manuales de economía ortodoxos antes de hablar de la eficiencia económica se expone el concepto de eficiencia técnica; este concepto define que un proceso productivo es técnicamente eficiente cuando con los factores productivos empleados se obtiene la máxima producción posible; así, un proceso productivo es técnicamente ineficiente si consume una cantidad mayor o igual de todos los inputs (tierra, trabajo, capital) que otro proceso y en ambos se obtiene una cantidad de output similar. Pero aunque esto proporciona una información valiosa al empresario, todavía tiene que decidir, dados unos procesos técnicamente eficientes, qué proceso elegir. De esta manera los economistas ortodoxos definen la eficiencia económica como aquel proceso productivo que, dados los distintos procesos técnicamente eficientes, es además el que menor coste asociado tiene dados unos precios de los factores de producción.

Es decir, la acepción ortodoxa de la eficiencia centra su atención en la minimización del despilfarro dada una tecnología y unos precios de mercado. Esta idea puede encontrarse en todos los manuales de microeconomía; de esta manera, Mankiw define ${ }^{2}$ la eficiencia como la «propiedad según la cual la sociedad aprovecha de la mejor manera posible sus recursos escasos»; en la misma línea, Walter Nicholson afirma ${ }^{3}$ que la eficiencia económica «existe cuando los recursos se asignan de tal forma que no es posible aumentar ninguna actividad sin reducir alguna otra», etc. En todas estas concepciones subyace, como hemos apuntado más arriba, una doble

\footnotetext{
2 Mankiw (2002), p. 504.

3 Nicholson (2003), p. 575.
} 
idea: por un lado que los agentes poseen ex ante plena información; y por otro que el objetivo del empresario y del proceso económico es evitar a toda costa el despilfarro; por este motivo podemos calificar de «estática» esta concepción de la eficiencia económica. Se trata de una dimensión muy limitada pues en pocas ocasiones los individuos cuentan con toda la información ex ante; además no tiene en cuenta el elemento temporal pues en ningún momento se incide en el propósito de aumentar esos recursos iniciales actuando de manera empresarial a lo largo del tiempo. Por ejemplo, esta dimensión de la eficiencia sería relevante en la gestión de un inventario donde toda la información está dada.

Así, el profesor Huerta de Soto sostiene ${ }^{4}$ que existe una plena similitud formal entre el concepto de eficiencia técnica y el concepto estático de eficiencia económica; la concepción estática de la economía reduce el concepto de eficiencia económica a un mero problema técnico de maximización que en todo caso podría solucionarse con un simple ordenador al que se le introdujeran los datos que siempre se suponen conocidos.

\section{La eficiencia dinámica}

Los economistas de la Escuela Austriaca han desarrollado ${ }^{5}$ una nueva dimensión de la eficiencia en la que se introduce la concepción dinámica del mercado propia de este enfoque donde el individuo-actor está sometido a una incertidumbre inerradicable y por lo tanto la información, los precios, etc., nunca están dados y donde el empresario creador tiene un rol esencial. Como podemos ver, esta dimensión de la eficiencia económica, denominada eficiencia dinámica, está íntimamente ligada al concepto de función empresarial; por ello, es preciso hablar previamente de ésta: definimos la función empresarial como la capacidad típicamente humana de darse cuenta de las oportunidades de ganancia que surgen en el entorno actuando en consecuencia para aprovecharse de las mismas; sus características principales son las siguientes:

\footnotetext{
${ }^{4}$ Huerta de Soto (2004), p. 25.

5 Huerta de Soto (2004), p. 26 y ss.
} 
- La función empresarial siempre genera nueva información; ésta es subjetiva, práctica, dispersa y tácita.

- La función empresarial es esencialmente creativa; todo desajuste social se plasma en una oportunidad de ganancia que queda latente para ser descubierta por los empresarios; cuando el empresario se da cuenta de una oportunidad de ganancia que ha pasado inadvertida crea nueva información en su mente que antes no existía.

- La función empresarial transmite información (expresa cuál es el desajuste y su solución).

- La función empresarial es coordinadora.

- La función empresarial es esencialmente competitiva; una vez es descubierta y aprovechada la oportunidad de ganancia con sus específicas coordenadas de tiempo y lugar ya no puede ser descubierta y aprovechada por otro empresario. Por tanto, el proceso empresarial es un proceso de rivalidad netamente competitivo en el que los empresarios rivalizan unos con otros por descubrir antes que nadie y aprovecharse antes que los demás de las oportunidades de ganancia que se van generando en su entorno.

- El proceso empresarial jamás se detiene ni agota. El acto empresarial, a la vez que coordina, crea nueva información que a su vez modifica en el mercado la percepción general de fines y medios de los actores implicados, lo cual da lugar a la aparición de nuevos desajustes que a su vez tienden a ser descubiertos y coordinados empresarialmente y así sucesivamente a lo largo de un proceso que jamás se detiene de expansión sin límites del conocimiento y los recursos, apoyado sobre un volumen de población siempre creciente y que tiende a ser tan coordinador como sea humanamente posible en cada circunstancia histórica concreta.

Así podemos definir la eficiencia dinámica como la capacidad de impulsar la creatividad y la coordinación empresarial. Dicho con otras palabras un ser humano, una empresa, una institución son más eficientes conforme más y mejor impulsen la creatividad y la coordinación empresarial. Lo relevante no es tanto evitar el despilfarro de unos medios dados, sino descubrir y crear continuamente 
nuevos fines y medios impulsando la coordinación y asumiendo que en todo proceso empresarial siempre surgirán nuevos desajustes por lo que cierto despilfarro es inevitable y consustancial a toda economía del mercado.

Hay que señalar que la dimensión dinámica de la eficiencia es la más relevante porque engloba a la dimensión estática de la eficiencia ya que es precisamente la misma fuerza de la función empresarial, que induce la eficiencia dinámica cuando crea y descubre nuevas oportunidades de ganancia, la que logra el máximo grado de eficiencia que sea humanamente posible en cada momento al coordinar los desajustes preexistentes.

\section{SEGUNDA PARTE: \\ LA ECONOMÍA EN UN CAMPO DE PRISIONEROS NAZI}

En esta segunda parte pretendo analizar desde un punto de vista austriaco el artículo de Radford haciendo especial hincapié en la función empresarial y en la eficiencia dinámica de los procesos de mercado que se desarrollaron de forma espontánea en los campos de prisioneros de la Segunda Guerra Mundial.

\section{Aclaraciones previas}

R.A. Radford fue un oficial británico que luchó en la Segunda Guerra Mundial (en adelante SGM) y fue capturado por los alemanes en 1943 o incluso en $1942^{6}$ cuando probablemente se encontraba combatiendo en la campaña de África del Norte o en el sur de Italia. Radford fue un economista marshalliano, pero pese a este hecho su artículo tiene un enorme valor pues es un análisis de primera mano sobre los procesos sociales y económicos que acontecieron en unas circunstancias históricas únicas

\footnotetext{
${ }^{6}$ Radford no habla mucho de sí mismo, pero en la página 196 de su artículo hace una breve referencia a los precios de la harina de centeno antes de 1943; podría ser que sencillamente le hubieran contado este detalle otros prisioneros más veteranos o que realmente fuera capturado en 1942 o ¡incluso antes!.
} 
como fueron los campos de concentración de prisioneros en la SGM.

Hay que señalar que los campos de prisioneros en los que estuvo Radford eran Offizierslager (campos de concentración alemanes para oficiales prisioneros de guerra). Estos campos eran distintos de los campos para soldados que no tenían rango militar de oficiales en los que era preciso trabajar y había un sistema de remuneraciones organizado por los alemanes; eran también radicalmente distintos de los campos de exterminio que existieron en la Alemania nazi durante la SGM. Estos campos de oficiales fueron completamente normales en todos los bandos combatientes ${ }^{7}$ y el trato que recibían los oficiales prisioneros de guerra era, teniendo en cuenta las circunstancias, relativamente bueno (al menos en los campos de concentración occidentales porque en la Unión Soviética, por ejemplo, las condiciones para los prisioneros de guerra fueron extremas).

Radford nos cuenta en su artículo que el primer campo en el que estuvo fue en el norte de Italia y con el paso del tiempo (y con el avance de las tropas Aliadas en Italia) fue trasladado a otros campos de prisioneros provisionales hasta que en otoño de 1943 fue trasladado a Alemania, en concreto al campo Stalag VIIA en Moosburg, Bavaria. El campo de prisioneros italiano era un pequeño campo de entre 1200 y 2500 prisioneros organizado en barracones de 200 prisioneros cada uno. El campo Stalag VIIA era mucho más grande, contando con 50.000 prisioneros de todas las nacionalidades (ingleses, franceses, italianos, yugoslavos, rusos, americanos, etc.); en este campo los prisioneros eran separados por nacionalidades como luego explicaré.

Es importante destacar que pese a estar prisioneros las categorías de rangos militares seguían siendo efectivas entre los prisioneros; es decir, en un barracón de prisioneros quien mandaba era el oficial con mayor graduación y el resto tenía que obedecer: un comandante (major, en el escalafón de mando del

7 Por ejemplo, Gran Bretaña tuvo numerosos campos de concentración pero en la mayoría de los casos los situó fuera de su territorio nacional, en sus territorios coloniales, por motivos de imagen pública. Probablemente Alemania hubiera hecho lo mismo si hubiera poseído colonias en la SGM. 
ejercito británico) seguía teniendo un rango mayor en la escala de mando que un capitán (captain), etc. Sin embargo, para seguir y comprender el texto de Radford (y para y seguir comprender este breve trabajo) no es preciso tener ningún tipo de conocimiento sobre burocracia y rangos militares de la SGM, tan sólo es importante saber que el mando dentro de los campos de prisioneros seguía siendo el mismo y por tanto los oficiales de mayor graduación tenían autoridad sobre el resto (de miembros prisioneros de su mismo ejército, se entiende). Podríamos decir, a efectos de este breve trabajo de análisis económico, que este hecho actuaba como un pseudo-Estado como más adelante veremos. Pese a esto, los prisioneros, en principio, eran propietarios legítimos de todos sus bienes y tenían, en general, libertad para hacer con ellos lo que quisieran.

Los prisioneros tenían tres fuentes de suministros:

- Las raciones suministradas por las autoridades alemanas del campo.

- El contenido de los paquetes de comida de la Cruz Roja.

- Paquetes privados.

Los dos primeros eran iguales para todo el mundo y se componían de bienes de consumo, leche condensada, jamón, mantequilla, galletas, carne de lata, chocolate, cigarrillos, etc. Los paquetes privados contenían un contenido variable: más ropa, más artículos de aseo, más cigarrillos, etc.

\section{La organización espontánea de la actividad económica en un campo de concentración}

El testimonio de Radford relata con bastante detalle el proceso de formación del mercado que él mismo describe como un proceso espontáneo ${ }^{8}$. Podemos intentar interpretar su testimonio desde

\footnotetext{
8 Radford (1945), p. 190, en concreto afirma «...the essential interest lies in the universality and the spontaneity of this economic life; it came into existence not by conscious imitation but as a response to the immediate needs and circumstances».
} 
un punto de vista austriaco, en concreto podemos utilizar las intuiciones de Carl Menger sobre el análisis del surgimiento de los

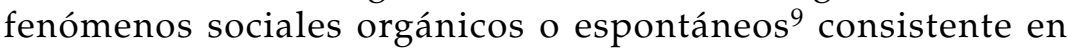
retrotraer estos fenómenos sociales a sus motivaciones individuales originarias. Las instituciones espontáneas no son resultado de causas social-teleológicas sino que son fruto no intencionado de numerosas acciones de sujetos económicos que persiguen sus propios intereses individuales (individual-teleológicos). Hay que destacar que el análisis de Radford es muy ilustrativo porque nos muestra el proceso social de desarrollo de muchos fenómenos económicos desde su surgimiento hasta su completo desarrollo. Me atrevo a decir que pocas veces en la Historia una misma persona ha sido testigo del proceso de surgimiento del dinero, de los mercados, del crédito, de contratos de compra/venta tal y como lo fue Radford por la sencilla razón que estos procesos suelen ser muy prolongados en el tiempo. Pese a esto, hay que matizar esta idea porque todos los prisioneros eran mayoritariamente occidentales del siglo XX y por tanto ya conocían instituciones económicas como el dinero, el contrato, el intercambio, el crédito, etc. Probablemente este hecho fuese la clave que explique la rápida aceptación por parte de todos los participantes en este proceso social de los descubrimientos económicos que los prisioneros más perspicaces iban ensayando con éxito.

Por tanto, es fundamental conceder un papel protagonista al individuo de carne y hueso que de manera empresarial actúa para modificar el presente y conseguir sus objetivos en el futuro $^{10}$. El protagonista del proceso social es el empresario que, a través de su función empresarial, crea ex novo nueva información y coordina este proceso; además el análisis quedaría incompleto si no se evaluara el grado de eficiencia dinámica de dicho proceso económico, esto es, analizando si el sistema fue capaz de

9 Menger (2006), p. 215 y ss. En este capítulo Menger esboza su teoría sobre la comprensión teórica de los fenómenos sociales que no tienen su origen en una convención social o en una imposición estatal, sino que son resultado no intencionado del proceso de mercado.

${ }^{10}$ Huerta de Soto (2005), p. 41. 
impulsar más y mejor la creatividad y la coordinación empresarial o por el contrario si no fue capaz de impulsarlas. Lo relevante es, por tanto, descubrir y crear continuamente nuevos fines y medios impulsando la coordinación y asumiendo que en todo proceso empresarial siempre surgirán nuevos desajustes, por lo que cierto despilfarro es inevitable y consustancial en todo proceso de basado en el intercambio contractual. Habiendo dicho todo esto, vamos a analizar cuál fue el proceso de surgimiento del mercado en los campos de prisioneros en la SGM.

\section{a) El surgimiento del trueque}

El punto de partida, como no podía ser de otra manera, se encuentra en la llegada de los hambrientos prisioneros al campo de prisioneros tras ser capturados. A todos se les daba una ración que incluía algo de comida, cigarrillos, y quizás algunos bienes de aseo personal e incluso ropa. Probablemente los prisioneros no fumadores pensaron en un primer momento que su dotación de cigarrillos no les podría servir para nada, así que seguramente, algunos de ellos llegaron incluso a regalarlos a sus compañeros quizás movidos por el compañerismo, la unidad de grupos, etc. Pero posiblemente, en seguida se dieron cuenta los prisioneros no fumadores de que merecía más la pena conservar esos cigarrillos inútiles y carentes de valor para ellos e intentar trocarlos por un poco de comida que le sobrara a algún fumador deseoso de cigarrillos. De la misma manera y dado que cada persona tiene una escala valorativa propia, probablemente surgieron de manera tímida y espontánea los primeros trueques (cambios directos) entre compañeros de litera (por así decirlo) durante los primeros días; cambios entre distintas comidas, cigarrillos, material de aseo, etc. Radford afirma que rápidamente, la buena voluntad se transformó en comercio ${ }^{11}$.

11 Radford (1945), p. 191; concretamente dice: «Goodwill developed into trading as more equitable means of maximising individual satisfaction.» 


\section{b) El surgimiento de la moneda-cigarrillo}

Estos primeros trueques sin duda eran muy beneficiosos para todos los prisioneros pero tenían el problema de la doble coincidencia de gustos; es cierto que la oferta de productos no debía ser muy amplia pero sí lo suficiente como para que este inconveniente llevara a los individuos a buscar individualmente soluciones. De esta manera, algunos individuos (los más emprendedores y creativos) se dieron cuenta de que los distintos bienes poseen distintos grados de liquidez: algunos bienes eran más fácilmente intercambiables que otros debido a su extendida demanda y viceversa. A raíz de este descubrimiento puramente empresarial, algunos individuos percibieron que si deseaban intercambiar, por ejemplo, un poco de carne por unas cuchillas de afeitar, era más sencillo y rápido intercambiar la carne por un tercer bien tan altamente demandado como eran los cigarrillos y después intercambiar estos cigarrillos por unas cuchillas de afeitar. ¿Por qué ocurría esto? Porque encontrar un propietario de unas cuchillas de afeitar que las quisiera intercambiar por un trozo de carne era más costoso (en términos de tiempo de búsqueda invertido) que encontrar un propietario de cigarrillos que quisiera intercambiarlos por carne y luego encontrar a un propietario de cuchillas de afeitar que quisiera intercambiarlas por los cigarrillos ${ }^{12}$.

Este aparente «rodeo» comercial que realiza el individuo no debe interpretarse como una irracionalidad o como un misterio, sino más bien como una consecuencia lógica del proceso de acción humana. Es decir, el individuo desea obtener la mercancía $\mathrm{B}$, y para lograrlo emprende un programa de acción que pasa por intercambiar su mercancía A por una mercancía más líquida (los cigarrillos), para posteriormente comprar B.

Los individuos que descubren esta propiedad de las mercancías y ensayan intercambios económicos en el mercado pronto perciben grandes ganancias que no hubieran podido lograr de otro modo. De esta manera, otros individuos observan a éstos y se dan cuenta de su descubrimiento económico y a través un proceso de

12 Ver Menger (1997) capítulo VIII o su trabajo «Sobre el origen del dinero», Menger (1892). 
imitación social comienzan a intercambiar sus mercancías poco a poco no por las mercancías que directamente satisfacen sus necesidades, sino por otras mercancías con mayor capacidad de venta como los cigarrillos, con las cuales podrán conseguir más rápidamente los bienes que desean en ulteriores transacciones. Estas mercancías más vendibles, más «dinerables», se convierten poco a poco en dinero en los diferentes mercados. Y de esta manera el cigarrillo fue seleccionado por el mercado para convertirse en el medio de intercambio generalmente aceptado entre los prisioneros, es decir, en dinero. Creo que es preciso insistir en dos características del proceso de surgimiento del dinero-cigarrillo:

1. Es un surgimiento espontáneo, no se trata de ninguna imposición de los oficiales de mayor rango ni de un acuerdo entre prisioneros previo.

2. La imitación social juegan un papel fundamental en el proceso a través del cual el dinero se extiende por todo el mercado.

El descubrimiento por parte de todos los individuos de que el cigarrillo era dinero elevó fuertemente la demanda de esta mercancía en el mercado, lo que tuvo dos consecuencias inmediatas: por un lado, este hecho incrementó enormemente la liquidez (ya de por sí elevada) de los cigarrillos y por tanto aceleró el proceso de aceptación general de los mismos como dinero; y por otro lado, el aumento de la demanda de los cigarrillos provocó un aumento de su poder de compra (de su precio) en el mercado.

La verdad es que, como indica Radford ${ }^{13}$, los cigarrillos tenían unas cualidades únicas para convertirse en dinero: eran homogéneos, razonablemente duraderos, y del tamaño adecuado para las pequeñas transacciones (y en paquetes para las grandes transacciones). Sin embargo, a Radford se le olvida destacar la característica más importante: que los cigarrillos eran una mercancía con una alta demanda no-dineraria. Si esto no hubiera sido así los cigarrillos jamás se hubieran convertido en dinero. Se me ocurre que probablemente las piedras que habría por

13 Radford (1945), p. 194. 
el campo de prisioneros eran igualmente homogéneas, más duraderas y del tamaño adecuado y seguramente eran finitas dada la limitada amplitud del campo, pero no se convirtieron en dinero debido a su nula demanda no-dineraria.

Es preciso señalar que el surgimiento del dinero en este mercado tuvo unos beneficios sociales enormes pues multiplicó fuertemente las posibilidades de intercambio entre los individuos e hizo posible el surgimiento del cálculo económico (que como luego veremos tuvo cierta importancia). Por tanto puedo decir, sin miedo a equivocarme, que el surgimiento del dinero-cigarrillo impulsó enormemente la eficiencia dinámica en el mercado del campo de prisioneros pues impulsó de manera muy significativa la creatividad y la coordinación empresarial. Creo que merece la pena hacerse la pregunta que tanto fascinaba a Carl Menger ${ }^{14}$ : ¿cómo es posible que fenómenos sociales tan sumamente útiles para el bienestar de la sociedad como por ejemplo el dinero, no hayan sido diseñados conscientemente por nadie, sino que sean el resultado no intencionado de acciones individuales que tan solo pretendían la satisfacción de sus propios intereses?

\section{c) Las peculiaridades de la moneda-cigarrillo}

Radford analiza en su trabajo los problemas que en su opinión tenía el hecho de que los cigarrillos tuvieran también fines no monetarios $^{15}$. Antes de nada hay que volver a insistir en que precisamente porque existía una demanda de cigarrillos no monetaria éstos se convirtieron en dinero; como antes he comentado las piedras al no ser valoradas por nadie no pudieron convertirse en dinero; lamentablemente, Radford no comprendía esta gran verdad: el surgimiento del dinero tiene su origen precisamente

\footnotetext{
14 Menger (2006), p. 222.

15 Radford (1945), p. 195; en concreto el autor afirma que: «Machine-made cigarettes were always universally acceptable, both for what they would buy and for themselves. It was this intrinsic value which gave rise to their principal disadvantage as currency, a disadvantage which exists, but to a far smaller extent, in the case of metallic currency; that is, a strong demand for non-monetary purposes.»
} 
en la mucha mayor liquidez de ciertos bienes con respecto a otros, y esta liquidez se fundamenta en su demanda universal no monetaria. Condenar el dinero precisamente por lo que lo ha convertido en dinero es un sinsentido. Pero dicho esto, sí que es cierto que la naturaleza "perecedera» de este bien económico era una fuente de inestabilidad económica en el mercado como ahora veremos (algo que no hubiera pasado en caso de tratarse de oro, claro); sin embargo, esta fue la mejor solución que pudo encontrar el mercado para superar el problema del trueque en estas circunstancias históricas concretas. Veamos qué hechos ocurrían en el mercado dada la peculiaridad de la moneda-cigarrillo:

En primer lugar, los cigarrillos podían ser fácilmente «aligerados» retorciéndolos con los dedos de forma que caían hebras de tabaco. Con estas hebras sustraídas podían llegar a hacerse nuevos cigarrillos a mano. Sin embargo el mercado respondió ante este problema rechazando los cigarrillos más delgados, o exigiendo algún cigarrillo extra en compensación en las transacciones. A pesar de esto, la moneda perdió calidad porque llegó un momento que todo el mundo deshacía sus cigarrillos y los volvía a liar para obtener más cigarrillos. Además de esto, muchos individuos compraban onzas de tabaco de pipa a un precio de 25 cigarrillos la onza; al parecer, con la habilidad suficiente se podían conseguir hasta 30 cigarrillos caseros por onza de tabaco de pipa (lo que suponen unos beneficios empresariales del 20\%).

En segundo lugar, existían varias marcas de cigarrillos pero las que se usaban en transacciones comerciales eran las de peores calidades; por ejemplo los cigarrillos Churchman $N . \stackrel{\circ}{1}$, que eran los más populares, raramente se veían en las transacciones. Radford concluye que este hecho responde claramente a la famosa ley de Gresham, porque la moneda mala (las marcas poco populares) sustituía en las transacciones a la moneda buena (las marcas más populares). Aparentemente este hecho contradice la formulación hayekiana de dicha ley; en concreto Hayek afirma que «...la ley de Gresham sólo actúa si las dos clases de dinero tienen que intercambiarse a una tasa prescrita de antemano.» ${ }^{16}$. En otro lugar

16 Hayek (1999), p. 180. 
Hayek afirma que: «Sin embargo, si los tipos de cambio fueran variables, el dinero de inferior calidad se valoraría a una cotización menor, y especialmente si amenazara con disminuir aún más de valor, la gente intentaría deshacerse de él lo antes posible.» ${ }^{17}$

¿Cómo es posible entonces que si los cigarrillos tenían distintas calidades, la moneda mala sustituyera a la buena si no había ningún tipo de cambio fijado de antemano entre ambas que infravalorara la buena y sobrevalorara la mala? ¿No deberían premiarse en las transacciones comerciales las marcas de mejor calidad con un mayor poder de compra? Radford nos da la pista sobre este asunto diciendo que pese a existir distintas calidades, en asuntos de monetarios, un cigarrillo era un cigarrillo ${ }^{18}$. Por tanto, desde una perspectiva hayekiana, cabría decir que institucionalmente estaba aceptado no exigir diferentes precios según la calidad (marca) del tabaco, por lo que ante esta restricción social, que actuaría como una tasa de intercambio entre cigarrillos prescrita de antemano de 1:1, los individuos atesoraban las mejores marcas y vendían sólo las peores; dicho de otra manera, esta presión social lo que hacía era sobrevaluar las peores marcas e infravalorar las mejores marcas; en consecuencia, los individuos reaccionaron empresarialmente frente a esta situación retirando de sus transacciones la moneda infravalorada (las mejores marcas) y pagando con la sobrevalorada (las peores marcas).

En tercer lugar, el campo de concentración estaba sometido a inflaciones y deflaciones ${ }^{19}$ fuertes y periódicas: cuando se repartían entre los prisioneros nuevos cigarrillos, aumentaban las existencias monetarias de la economía (inflación); pero progresivamente, a medida que pasaban los días, los prisioneros fumadores

17 Hayek (1999), p. 212. Como podemos ver la formulación de la ley de Gresham que utiliza Radford es la formulación ortodoxa que no tiene en cuenta que la condición necesaria para que opere esta ley es que exista una tasa de intercambio fijada de antemano entre ambas monedas que infravalore una y sobrevalore otra.

18 Radford (1945), p. 194; en concreto el autor afirma que: «Cigarettes were also subject to the working of Gresham's Law. Certain brands were more popular than others as smokes, but for currency purposes a cigarette was a cigarette.»

19 En este texto utilizo el sentido original del concepto de inflación (deflación), que puede definirse como un aumento (disminución) de las existencias monetarias en una economía. Mises (2004), pp. 507-509. 
iban fumándose los cigarrillos y por tanto disminuían las existencias monetarias (deflación). Esto provocaba que los días en que se inyectaban nuevos cigarrillos se produjeran, ceteris paribus, fuertes disminuciones en el poder adquisitivo del dinero (provocando grandes subidas en los precios nominales en el mercado) seguidas de un progresivo aumento en el poder adquisitivo de los mismos a medida que iban pasando los días y las existencias de cigarrillos se reducían (provocando progresivos descensos en los precios nominales de las mercancías).

Radford señala que un hecho especialmente dramático ocurría cuando llegaban paquetes privados para los prisioneros (esto ocurría una vez cada trimestre); estos días, según el autor, podían inyectarse fácilmente cientos de miles de cigarrillos con lo que el poder de compra de los cigarrillos se desplomaba rápidamente para luego aumentar lentamente en una primera etapa y rápidamente en una segunda etapa a medida que disminuían las existencias de cigarrillos (provocando consecuentes aumentos y progresivas disminuciones de todos los precios nominales en el mercado).

Nuestro autor señala que, dejando a un lado estos días excepcionales de reparto masivo de cigarrillos a través de los paquetes privados, si había un abastecimiento regular y previsible de los cigarrillos, las perturbaciones tan peculiares de este sistema monetario no causaba graves problemas; sin embargo, cuando esta regularidad se interrumpía y dejaban de suministrarse cigarrillos durante un periodo de tiempo prolongado, ceteris paribus, aumentaba fuertemente el poder adquisitivo de los cigarrillos (disminuyendo fuertemente los precios nominales) $\mathrm{y}$, finalmente, la destrucción de la moneda llevaba temporalmente a la desaparición del cambio indirecto y a la vuelta al trueque lo que provocaba una significativa disminución del volumen de intercambio en todo el campo; el cambio indirecto resurgía rápidamente cuando se repartían nuevos cigarrillos en el campo. Estas irregularidades en el abastecimiento de cigarrillos, que se produjeron con mayor frecuencia e intensidad a medida que se aproximaba el final de la guerra fueron la causa de la quiebra de muchos negocios y de la ruina de muchos comerciantes. Este fue, por tanto, el principal factor de inestabilidad económica. 
Cabe preguntarse si estos procesos inflacionarios provocaban redistribuciones en la riqueza de los individuos o no. Por un lado, hay que aclarar que los repartos de cigarrillos en principio aumentaban la riqueza global de la economía porque recordemos que el cigarrillo era un bien demandado por los consumidores para fines no monetarios. Por otro lado, la igualdad en el reparto de cigarrillos eliminaba cualquier efecto redistributivo porque todos recibían la misma cantidad de cigarrillos y al mismo tiempo. Sin embargo, los días que llegaban paquetes privados dado que eran desiguales y no todo el mundo los recibía las cosas cambiaban; probablemente ${ }^{20}$ en los primeros repartos de paquetes privados se produjeron grandes redistribuciones de la riqueza, los individuos que recibían grandes cantidades de cigarrillos podían comprar bienes y servicios ese día a precios del día anterior sin que los vendedores se dieran cuenta de que la situación del mercado había cambiado, provocándose una clara redistribución de la riqueza; sin embargo, también probablemente, esto sólo ocurrió en los primeros repartos porque en los sucesivos repartos de paquetes privados los agentes habrían aprendido y seguramente actuarían empresarialmente exigiendo mayores precios nominales por sus bienes y servicios.

\section{d) La formación del mercado}

Al mismo tiempo que se iban generalizando los trueques entre prisioneros del mismo barracón e iba surgiendo el dinero-cigarrillo, algunos individuos, los más perspicaces, se dieron cuenta de la posibilidad de incrementar su riqueza personal visitando distintos barracones y aprovechándose de las grandes disparidades de precios relativos que había entre barracones. El mercado no era único sino que estaba compartimentado en barracones y esto hacía que hubiera grandes oportunidades de ganancia para los primeros empresarios que conectaran todos estos submercados ${ }^{21}$.

20 Radford no trata este tema en ningún lugar de su artículo.

${ }^{21}$ Este es un claro ejemplo de la naturaleza rival y competitiva de la función empresarial; es decir, una vez que se descubre por el actor una determinada oportunidad 
En concreto, Radford cuenta que en el primer campo de prisioneros, el de Italia, había un cura que daba vueltas por todos los barracones y que por la mañana salía con una lata de queso y cinco cigarrillos y volvía a la cama con un paquete entero además de su queso y sus cigarrillos originales; este tipo de historias eran normales y ciertamente despertaron el interés de todos los prisioneros que rápidamente se dieron cuenta de las posibilidades de incrementar su patrimonio y mejorar su calidad de vida dentro del campo a través del comercio. Este es un claro ejemplo de la relevancia de la dimensión dinámica de la eficiencia; el objetivo no es ya evitar el despilfarro de una dotación de recursos dados, sino incrementar este patrimonio a través del intercambio y de la acción empresarial. De esta manera se fue formando el mercado en dos etapas:

En una primera etapa, la gente iba de barracón en barracón pregonando sus precios de compra y de venta: «queso por siete (cigarrillos)», «carne por nueve (cigarrillos)», etc. Según Radford este sistema era «una locura» en las horas inmediatas a la entrega de paquetes.

En una segunda etapa, se sustituyó este sistema por la colocación de un Tablón de Anuncios de Intercambio en cada barracón: allí figuraban el nombre, el número de habitación, las ofertas y demandas de cada persona que quisiera participar. Cuando un trato se cerraba se tachaba en el Tablón. Una vez se generalizó este sistema, los precios comenzaron a ser bien conocidos y tendieron a igualarse; en consecuencia, las grandes ganancias que obtenían empresarios arbitristas como el cura antes mencionado menguaron; sin embargo, como menciona Radford, siempre había oportunidades para un comerciante avispado. Creo que este mecanismo institucional de mercado fue enormemente eficiente (en un sentido dinámico) pues posibilitaba a los individuos la rápida obtención de información relevante sobre la situación concreta del mercado; con esta información los individuos podían percibir más fácilmente las oportunidades latentes de beneficio empresarial; por tanto el Tablón de Anuncios de

de ganancia y éste actúa para aprovecharla, dicha oportunidad desaparece y ya no puede ser apreciada y aprovechada por otro, Huerta de Soto (2005), p. 77 y ss. 
Intercambio impulsaba fuertemente la creatividad y la coordinación empresarial del proceso social.

Es importante señalar que esta formación del mercado único en el campo de prisioneros requería cierto tiempo y ciertas perspectivas por parte de los prisioneros de que estarían en ese campo de prisioneros de manera prolongada; Radford menciona que en los campos de prisioneros que tenían un carácter provisional este mercado tan perfeccionado nunca lograba formarse porque estos campos eran siempre caóticos y poco confortables, «la gente estaba hacinada, nadie sabía donde vivían los demás y nadie se tomaba la molestia de averiguarlo» 22 . En estos campos, la organización económica era tan débil que el autor nos cuenta que una misma lata de salmón podía variar de precio entre dos y veinte cigarrillos de un extremo a otro de un mismo barracón.

\section{e) La conquista de nuevos mercados}

Había muchas oportunidades de ganancia para empresarios perspicaces. Creo que merece la pena destacar dos ejemplos que Radford cuenta en su artículo.

Los Sikhs son ciudadanos de la India que lucharon en el bando británico (recordemos que durante la SGM la India aún era colonia de Gran Bretaña). Por motivos religiosos no podían comer carne, por lo que este bien carecía de valor para ellos; además las barreras lingüísticas eran un importante obstáculo para el comercio. Algún prisionero occidental se dio cuenta de este hecho y capitalizó sus conocimientos de Urdu (idioma de los Sikhs) comprándoles carne a los Sikhs a cambio de otros bienes como mantequilla y mermelada. Este es un claro ejemplo de la función coordinadora y creativa de la empresarialidad; antes de este comercio, para los Sikhs probablemente debía ser una maldición e incluso un insulto que se les repartiera carne; un empresario (Sikh o británico) se dio cuenta de que podía aprovechar esta situación comprando carne barata a los indios y vendiéndola cara en la zona británica. Así, este acto empresarial creó nueva información en

22 Radford (1945), p. 191. 
la mente del primer empresario que se dio cuenta de este desajuste social; y cuando este empresario se puso en contacto tanto con los Sikhs como con los británicos, creó también en sus mentes nueva información que antes no existía; ahora para los Sikhs la carne ya no era una maldición sino que era un bien económico que era oportuno economizar porque había una demanda para él; en la zona británica, este acto empresarial hizo que los británicos se dieran cuenta de que había más carne en el mercado y que por tanto podían consumirla con más frecuencia. Este acto empresarial transmitió esta información de nueva creación a través del sistema de precios: en la zona india, los precios de la carne subieron (ya fuera en términos de cigarrillos o de otros productos) y en la zona británica bajaron, modificando el comportamiento de unos y otros. Este acto empresarial tuvo un efecto de coordinación y ajuste porque tanto los Sikhs como los británicos aprendieron a actuar unos en función de otros ${ }^{23}$ a pesar de hablar idiomas diferentes y de no conocerse. Los beneficios empresariales de este comercio en un primer momento fueron enormes, pero poco a poco disminuyeron a medida que estas operaciones se hicieron conocidas y más empresarios participaron en él. Según Radford, a pesar de esto, el contacto con los indios tuvo su valor hasta el final debido a la barrera del lenguaje ${ }^{24}$.

Como segundo ejemplo de las grandes posibilidades de ganancia que tenían los empresarios perspicaces podemos destacar este: en el campo Stalag VIIA de Alemania había unos 50.000 prisioneros y estaban separados en zonas por nacionalidades. Sin embargo, era muy sencillo sobornar con unos pocos cigarrillos a un guardia alemán para poder pasar de una zona a otra y así exportar e importar excedentes de una zona a otra. En una de estas incursiones, algunos prisioneros de la zona británica descubrieron que en la zona francesa había un extracto de café a un precio fantástico y algunos aprovecharon este descubrimiento empresarial e hicieron pequeñas fortunas con esto ${ }^{25}$. Al parecer,

${ }^{23}$ Huerta de Soto (2005), p. 66 y ss.

24 Radford (1945), p. 193.

25 Dado que tan solo se permitía el paso a algunos miembros de la zona británica a la zona francesa, estos eran los únicos que podían acceder al extracto de café 
gran parte del café (el no vendido dentro del campo de prisioneros) era exportado por los franceses al mercado negro de Munich donde se vendía a precios elevados; algunos franceses acumularon sustanciales sumas de marcos con estas operaciones.

Estos son solo algunos de los ejemplos de los múltiples mercados que fueron abriendo los individuos más emprendedores motivados por la búsqueda del beneficio en un proceso social claramente competitivo y rival, porque solamente los primeros en percibir las oportunidades de ganancia y aprovecharse de ellas eran los que percibían los beneficios. Por tanto, los empresarios que participaron en estas transacciones actuaron de una forma extremadamente eficiente (en un sentido dinámico) porque impulsaron enormemente la coordinación y la creatividad empresarial en el mercado.

\section{f) El surgimiento del mercado de trabajo}

A medida que el mercado se fue desarrollando, algunos individuos se dieron cuenta que podían aprovechar un recurso que todos tenían en abundancia, y más en un campo de prisioneros: el tiempo. De esta manera surgieron de forma espontánea todo tipo de anuncios de prisioneros ofreciendo servicios laborales variados: lavanderos, planchadores de trajes, retratos al óleo, servicios, especialistas en comercio de relojes, de ropa, de alimentos, de comercio con los Sikhs, especuladores, arbitristas e intermediarios de todo tipo; incluso se constituyeron algunas «empresas» como por ejemplo una cafetería que ofrecía té, café y cacao, etc.

Radford cuenta que la cafetería llegó a tener un volumen de actividad importante y que incluso contrató camareros, compraba a través de intermediarios todas las materias primas que necesitaba e incluso contrató los servicios de un contable.

francés por lo que percibieron enormes beneficios; mucha gente se quejó de esta situación y los mandos británicos decidieron regular este comercio y se adjudicó a cada grupo de camas una cuota de artículos que podían ofrecer y la transacción se llevaba a cabo por representantes acreditados del recinto inglés con derechos de monopolio. 
Lamentablemente esta cafetería quebró debido a los fuertes y periódicos cambios en los precios que acontecían en mercado que dificultaban el cálculo económico y la anticipación empresarial de la situación futura del mercado.

Radford habla también de un especulador que se hizo muy famoso en todo el campo, llamado Sam, que consiguió una elevada reputación: compraba raciones los días de entrega y las vendía los últimos días antes de la siguiente entrega. Sam también actuaba como arbitrista entre estos dos periodos aprovechando las diferencias de precios entre los distintos Tablones de Precios; según nuestro autor, este empresario tenía un conocimiento profundo de los precios, mercados, nombres, paquetes privados, etc. Por tanto Sam impulsaba la coordinación y la creatividad empresarial en el mercado por lo que era muy eficiente (en un sentido dinámico). Lamentablemente Sam quebró al cometer el error típicamente empresarial de equivocarse al anticipar la situación del mercado: disponía de una importante partida de azúcar morena cuando el precio de esta se desplomó por una inesperada llegada de paquetes de azúcar al campo. Este ejemplo nos muestra la gran incertidumbre inerradicable a la que estaba sometida toda actividad mercantil.

Creo que es de vital importancia señalar el importante papel que tuvo la existencia de la moneda-cigarrillo para la acción empresarial de todos los individuos en el mercado. Sin ella el cálculo económico ${ }^{26}$ hubiera sido imposible y esto habría dificultado enormemente cualquier acción económica en el mercado porque los individuos no hubieran podido estimar el resultado monetario de los distintos cursos de acción. Por tanto, el cálculo económico es una poderosa herramienta empresarial que permite hacer cálculos complicados y enjuiciar el éxito o fracaso de proyectos empresariales pasados o futuros.

26 «Por cálculo económico hemos de entender por tanto, todo cómputo estimativo en unidades monetarias sobre los resultados de los distintos cursos de acción» Huerta de Soto (2005), p. 72. 


\section{g) El surgimiento del crédito en el mercado}

Algunos individuos perspicaces se dieron cuenta de que podían anticipar bienes a prisioneros con una preferencia temporal más alta que la suya. Así muchos individuos ofrecían productos a dos precios distintos, un precio en cigarrillos a pagar en el momento o un precio en cigarrillos a pagar en el futuro. Las raciones normalmente se repartían el lunes y el jueves; de esta manera el «pan ahora» era una mercancía distinta que «pan el lunes» o que «pan el jueves», y lógicamente su precio era mayor conforme mayor fuese el plazo de venta y probablemente, cuanto mayor fuera el riesgo de cobro (ya fuera por la posibilidad de que las raciones futuras no se repartieran con regularidad debido a motivos de desabastecimiento propios de una situación bélica o por la dudosa palabra del prestatario). También se compraban raciones futuras descontando su valor futuro en cigarrillos. De esta manera, por ejemplo, Sam pagaba por adelantado sus compras de entregas futuras de azúcar.

Así, este mercado de crédito impulsaba la creatividad y la coordinación empresarial porque permitía a personas con distintas preferencias temporales ajustar su comportamiento en un proceso mutuamente beneficioso. Por tanto, este mercado era muy eficiente (en un sentido dinámico).

\section{h) Movimientos de precios}

En esta economía tan singular, se producían constantes mutaciones en los precios por diversos motivos. Aquí trato de explicar las más importantes; primero merece la pena hablar de las mutaciones en precios de origen estrictamente monetario:

a) Las constantes inflaciones y deflaciones que continuamente se sucedían debido a la naturaleza específica del dinero-cigarrillo y a la irregularidad y brusquedad del abastecimiento provocaban paralelos aumentos y disminuciones de los precios, como ya hemos apuntado en un apartado anterior.

b) Por otro lado, las expectativas sobre la llegada de más cigarrillos influían fuertemente en los precios: así, si se corría el 
rumor de que una nueva remesa de provisiones iba a llegar, los individuos decidían deshacerse de sus reservas de cigarrillos y comprar raciones para consumirlas, por lo que se iniciaba una tendencia al aumento de los precios nominales de la economía. Aunque también había una contra-tendencia a este aumento de precios, motivada por el repentino entusiasmo de los prisioneros fumadores que hartos de racionar sus cigarrillos, decidían consumirlos ante la expectativa de recibir nuevos cigarrillos pronto, lo que provocaba una deflación (disminución de las existencias de cigarrillos) y una consiguiente tendencia a la reducción de los precios nominales de la economía. El efecto que más fuerza tuviese sería el que determinara si se producían aumentos o disminuciones en el poder de compra de la moneda.

Pero también había hechos que provocaban mutaciones en los precios que no tenían un origen estrictamente monetario ${ }^{27}$; por ejemplo:

a) Las noticias sobre la marcha de la guerra provocaban cambios en las expectativas de los participantes en el mercado y consecuentes cambios en los precios relativos.

b) La llegada de nuevos prisioneros hambrientos aumentaba el número de demandas hacia los bienes alimenticios en perjuicio de la demanda de cigarrillos, materiales de aseo, relojes, ropa, etc., por lo que ceteris paribus, había una tendencia a que los precios de los alimentos aumentaran y el resto disminuyeran ${ }^{28}$.

\footnotetext{
27 Böhm-Bawerk (1998), pp. 384 y ss.

${ }^{28}$ Radford comete un error teórico al decir que. «The general price level was affected by other factors. An influx of new prisoners, proverbially hungry, raised it.» Es ilegítimo sostener que el aumento de la demanda de los bienes alimenticios aumentase todos los precios de la economía porque en ausencia de inflación no pueden aumentar todos los precios de una economía. Cuando llegaban nuevos prisioneros hambrientos aumentaría el precio de los alimentos y probablemente bajarían los precios de otros bienes, en concreto de los bienes que los hambrientos prisioneros ofrecieran a cambio de esa comida extra que demandaban: material de aseo, ropas (recordemos que cada prisionero recibía a la entrada del campo un paquete de bienes que no eran exclusivamente comida), servicios de trabajo, relojes, joyería, etc.
} 
c) Cambios en las preferencias de los participantes en el mercado, como por ejemplo el que se daba cuando llegaba el verano: como hacía más calor la demanda de cacao disminuía y la demanda de jabón aumentaba, provocando variaciones en sus precios.

d) La entrega de nuevas raciones aumentaba la abundancia relativa en el mercado de algunos bienes, lo que provocaba modificaciones en los precios relativos de los mismos.

e) En agosto de 1944 la cantidad suministrada de paquetes y cigarrillos se redujo drásticamente a la mitad; esto provocó fuertes cambios en los precios relativos debido a que la demanda no monetaria de cigarrillos era más intensa que la de alimentos, por lo que los precios de los alimentos se redujeron ligeramente en relación a los cigarrillos.

f) Otros cambios en la demanda provocados por descubrimientos empresariales como el que ocurrió con las pasas y el azúcar: algunos empresarios-actores descubrieron que con pasas y azúcar se podía conseguir un licor de considerable potencia, por lo que rápidamente subió la demanda de estos bienes y consecuentemente subieron sus precios. En otro lugar, el autor afirma que antes de 1943, las latas de harina de centeno estaban consideradas como un lujo escaso y muy buscado; sin embargo a partir de 1943 se convirtieron en un bien muy corriente debido al aumento de las mismas en las raciones otorgadas a los prisioneros, por lo que su precio disminuyó.

Todos estos ejemplos ilustran adecuadamente el marco cambiante al que se enfrentaban los prisioneros. Como puede verse, el mercado que describe Radford estaba afectado por fuertes perturbaciones y constantes cambios donde surgían continuamente nuevas oportunidades de beneficio que eran aprovechadas por los empresarios más perspicaces. En este constante desequilibrio económico los empresarios jugaban un papel coordinador y creativo que permitía impulsar el mayor grado de eficiencia que era humanamente posible en cada momento coordinando los desajustes preexistentes y creando nueva información en la mente de todos los actores. 


\section{La zona británica}

En este último apartado pretendo comentar algunos hechos económicos que se dieron con exclusividad en la zona británica promovidos por los oficiales británicos.

\section{a) La Tienda}

En la zona británica se organizó una Tienda ${ }^{29}$ sin fines lucrativos controlada por la asociación de oficiales del ejército. El funcionamiento de la Tienda era sencillo: voluntariamente cada cual podía dejar sus excedentes de ropa, artículos de tocador y comida hasta que eran vendidos a un precio fijado en cigarrillos. Se tomaba como referencia un precio de mercado. Las ventas en la Tienda solían ser lentas pero garantizaban un buen precio; si alguien necesitaba urgentemente liquidar sus existencias siempre podía retirarlas de la tienda y venderlas por su cuenta a un precio menor; y si en cualquier momento el precio fijado en la Tienda era inferior al precio de mercado siempre se podía retirar los bienes que se había puesto a la venta y venderlos más caros de forma privada.

En mi opinión, la Tienda sí que era un mecanismo institucional que impulsaba la eficiencia dinámica del mercado pues fomentaba que personas con poca capacidad empresarial (piénsese en un prisionero tullido, etc.) pudiese participar en el mercado de una forma más cómoda y poco costosa (en términos de molestias para buscar compradores y vendedores), y también podía servir como fuente de suministro a individuos con grandes necesidades de provisiones y con mucho capital en forma de cigarrillos que quisieran comenzar un negocio (una cafetería,...). Además siempre podía servir como referencia a los individuos con un escaso conocimiento sobre precios en el mercado, etc. En

${ }^{29}$ Quizás esta Tienda fue una etapa superior del desarrollo comercial en la zona británica, pero he decido no incluirla en dicho desarrollo debido a que su origen estaba en la asociación de oficiales del ejército y no tuvo un origen completamente mercantil. 
cualquier caso, dada la voluntaria participación en la misma, la Tienda pasó a ser una institución más del proceso de mercado y el éxito que tuvo fue una buena prueba de su utilidad.

\section{b) El Restaurante y la creación del «Marco fuerte»}

Alrededor del día $D$ la comida y los cigarrillos eran abundantes, los negocios prosperaban y había mucho optimismo en el campo. Por este motivo, el Comité de Entretenimientos ${ }^{30}$ consideró oportuno lanzar un Restaurante donde se vendiera comida y bebidas calientes y actuara una banda de conjuntos y variedades.

Todos los materiales se compraban a precios de mercado y los beneficios se destinaban a engrosar un fondo para sobornos a guardias alemanes ${ }^{31}$. Con el fin de evitar los negativos efectos de las periódicas inflaciones y deflaciones de cigarrillos que sacudían el campo a los oficiales se les ocurrió la idea de crear una nueva moneda ${ }^{32}$ : el Marco fuerte.

El Marco fuerte era un billete ${ }^{33}$ en el sentido clásico del término: eran trozos de papel que la Tienda y el Restaurante expedían y que se podían adquirir a cambio de bienes; estos billetes estaban garantizados al $100 \%{ }^{34}$ por la Tienda y en cualquier momento un tenedor de Marcos fuertes podía hacer efectiva la deuda que la Tienda había contraído con ellos canjeando estos billetes

30 Sin duda se trata de un organismo creado dentro del marco de la jerarquía militar.

31 Radford (1945), p. 196; nótese que habríamos de considerarla una empresa pública por el origen de su fundación y sus objetivos.

32 También se pretendió fomentar el comercio estable.

33 En terminología de Mises, estos billetes de banco serían dinero-crédito; Mises (2004), p. 514

34 Radford afirma en concreto que: «The BMk [Marco fuerte] was backed 100 per cent. by food: there could be no over-issues, as is permissible with a normal bank of issue, since the eventual dispersal of the camp and consequent redemption of all BMk.s was anticipated in the near future.» Es decir, la plena garantía de los depósitos es defendida por Radford no como una necesidad jurídica basada en el derecho consuetudinario, sino como algo excepcional dada la previsible situación de futura liquidación de los Marcos fuertes por sus tenedores a cambio de los bienes-reserva que representaban una vez terminada la guerra. 
por los bienes con los que estaban respaldados. Dada la naturaleza perecedera de los alimentos en realidad a lo largo del tiempo se iba cambiando la composición de los bienes de la reserva del $100 \%$ por razones obvias; pero seguramente se tendieron a utilizar como bienes-reserva frutos secos, azúcar y otros bienes menos perecederos; pese a esto el tenedor del billete no tenía garantizado un bien concreto a cambio del mismo sino un valor de mercado concreto por unidad de Marco fuerte. En un principio estos billetes tuvieron una enorme aceptación e incluso rivalizaron con los cigarrillos en su condición de dinero, pero la crisis de agosto de 1944 hizo que muchos tenedores prefiriesen cobrar los billetes y comerse sus raciones. Además los cambios en la estructura de precios relativos hicieron que el Marco fuerte se depreciara respecto al cigarrillo cuando las raciones y la asignación de cigarrillos se redujeron a la mitad. Por estos motivos los individuos huyeron del Marco fuerte y este dejó de tener demanda en el mercado.

En mi opinión, el Marco fuerte fue una buena idea y creo que evidencia la importancia que tenía el intercambio en la vida de estos prisioneros. De haberse ganado la aceptación de los consumidores y de haber logrado un patrón monetario más estable (y en consecuencia unos precios más estables en el mercado), el Marco fuerte seguramente hubiera sido un magnífico instrumento muy eficiente (en un sentido dinámico) porque probablemente hubiera impulsado más la creatividad y la coordinación empresarial y hubiera reducido los errores de cálculo económico que cometieron muchos individuos dada la gran variabilidad de los precios. Si hubiera triunfado en la zona británica quizás se hubiera extendido por el resto de zonas del campo de prisioneros, lo que hubiera sido la prueba definitiva de su éxito.

\section{c) Intervencionismo y controles de precios: la fatal arrogancia}

Los oficiales de la zona británica, capitaneados por el Oficial Médico (que estaba preocupado porque algunos prisioneros vendiesen una parte demasiado grande de sus raciones en detrimento de su salud), trazaron un plan para controlar las ventas de 
alimentos. Además, había un proyecto de mantener el Marco fuerte a la par con los cigarrillos para aumentar su aceptabilidad; y el control de precios parecía el camino adecuado para ello dentro de la mentalidad voluntarista tan característica de los cuerpos militares. Además, según Radford, contaban con el apoyo de la opinión pública que se mostraba a favor de un precio «justo y estable» en el mercado ${ }^{35}$.

Para ello los Tablones de Anuncios de Intercambio pasaron al control de la Tienda (es decir, bajo el control de la asociación de oficiales del ejército británico); se estableció que los anuncios del Tablón que diferían en más de un $5 \%$ del precio podían ser suprimidos por la autoridad y las ventas fuera de este intervalo de precios no estaban permitidas. Los precios oficiales se fijaban bajo la orientación del mercado y bajo la orientación el Oficial Médico.

Nuestro autor afirma que este sistema al principio funcionó exitosamente; pero comenzó a fallar cuando se producía un cambio en el mercado provocado por una fuerte inflación o deflación, o cuando las circunstancias del mercado cambiaban: la estructura de precios oficiales era demasiado rígida como para responder a los cambios de precios, tanto absolutos como relativos; cuando había una disminución o un aumento general de los precios las autoridades británicas tardaban en reducir o aumentar la escala de precios demasiado tiempo y, además, lo que hacían era cambiar proporcionalmente los precios sin tener en cuenta los cambios en los precios relativos de los productos, mientras que en el mercado la estructura relativa de los precios sí que cambiaba con bastante frecuencia. Las autoridades reaccionaban frente a la proliferación de anuncios con precios no oficiales en los tablones tachándolos y esto llevó a la aparición de un mercado negro que tuvo un rápido crecimiento. Con el tiempo, tras haberse demostrado el fracaso del nuevo sistema, la opinión pública lo rechazó y las autoridades desistieron en su intento de fijar precios.

Este intento de controlar el mercado fue un ataque directo a la eficiencia dinámica del mismo: al controlar los precios del

35 Radford (1945), p. 198. 
Tablón de Anuncios de Intercambio lo que se consiguió fue anular este mecanismo de mercado de enorme eficiencia pues se les negó a los individuos la posibilidad de obtener rápidamente información relevante sobre la situación del mercado. El Tablón de Anuncios de Intercambio pasó de ser el mejor reflejo de la situación del mercado a ser un torpe seguidor del mismo; el control del Tablón actuó como un bloqueo a la creatividad y a la coordinación empresarial, pues una vez la situación real del mercado cambiaba las autoridades militares británicas no eran capaces de recoger y sintetizar la información del mercado dadas las características de esta misma (táctica, dispersa y no articulable). Además causó un gran perjuicio a todos los participantes del mercado pues ya no pudieron percibir la información económica que el Tablón les proporcionaba cuando funcionaba de forma libre. Y probablemente a muchos individuos estos precios falsos que las autoridades fijaban les confundieron en sus actuaciones económicas. Como respuesta a este ataque contra el proceso de mercado los propios individuos reaccionaron desafiando a la autoridad militar e intercambiando productos en un creciente mercado negro. Pero estos intercambios sin duda tenían asociados unos costes de información muy grandes que provocaron fuertes pérdidas de bienestar a sus participantes. En consecuencia, podemos decir que esta intervención fue completamente ineficiente en un sentido dinámico.

\section{Los últimos meses del campo y la liberación}

A partir de agosto de 1944 hasta el final de la guerra el flujo de suministros se redujo drásticamente provocando un fuerte descenso del nivel de vida de los prisioneros. Los cigarrillos comenzaron a escasear de manera alarmante, hecho que ocasionó un fuerte aumento del poder adquisitivo de los mismos (y una fuerte bajada en los precios de todas las mercancías) y un retorno a una economía basada en el trueque.

Para fortuna de todos los prisioneros el 12 de abril de 1945 la 30. a División de Infantería de los EEUU liberó el campo, terminando de esta manera con la dura situación de escasez de 
productos de primera necesidad que padecían los prisioneros así como con su cautiverio. Acabada la guerra, todos los prisioneros pudieron volver a sus casas en sus respectivos países para continuar sus vidas allí donde las dejaron cuando estalló la SGM.

\section{TERCERA PARTE: CONCLUSIONES}

A lo largo de este breve trabajo he intentado interpretar el testimonio de Radford a la luz de la concepción austriaca del proceso de mercado haciendo hincapié en la eficiencia dinámica de los procesos sociales que se dieron en los campos de prisioneros de la SGM.

Me parece interesante resaltar cómo la fuerza coordinadora y creativa de la empresarialidad pudo resolver innumerables problemas económicos: pasando del trueque al dinero, creando mecanismos de crédito, uniendo mercados, adaptándose a las continuas perturbaciones, etc. Hay que insistir en que el proceso social sólo puede estudiarse partiendo del ser humano individual de carne y hueso que actúa empresarialmente para cambiar su presente y satisfacer sus necesidades.

Merece la pena volver a comentar el fracaso de las autoridades militares británicas en su intento de controlar los precios del mercado; en un acto de fatal arrogancia, las autoridades creyeron poder sustituir la función coordinadora del sistema de precios y obviamente se equivocaron: sólo consiguieron coartar la iniciativa empresarial y el libre funcionamiento del mercado, creando fuertes desajustes en el mercado que disminuyeron el bienestar de los prisioneros británicos de manera significativa.

Finalmente, concluyo que la dimensión dinámica de la eficiencia económica es mucho más relevante que su dimensión estática pues en el mercado la información siempre está en continuo cambio y nunca está dada: lo más relevante no es evitar el despilfarro de unos recursos iniciales dados sino incrementar la propia riqueza descubriendo continuamente nuevos fines y medios que impulsen la coordinación y la creatividad en el mercado; creo 
que los procesos sociales que se desarrollaron de manera espontánea en los campos de prisioneros de la SGM ilustran muy bien esta idea.

\section{REFERENCIAS BIBLIOGRÁFICAS}

BÖHM-BAWERK, E. (1998). Teoría positiva del capital, Ediciones Aosta, Madrid.

HAYEK, F.A. (2001). Ensayos de teoría monetaria II, Unión Editorial Madrid.

Huerta De Soto, J. (2004). «La teoría de la eficiencia dinámica», en Procesos de Mercado n. ${ }^{-} 12004$, pp. 11-72.

- (2005). Socialismo, cálculo económico y función empresarial, Unión Editorial, Madrid.

Mankiw, N.G. (2002). Principios de economía, McGrawHill, España, 2. ㄹ Edición.

Menger, C. (1997). Principios de economía política, Unión Editorial, Madrid, 2. 를ición.

- (2006). El método de las ciencias sociales, Unión Editorial, Madrid.

- (1892). «On the origin of money», en Economic Journal, junio de 1982, pp. 239-255. Reeditado en el vol. I de Israel Kirzner (ed.), Classics in Austrian Economics: A sampling in the history of a tradition.

Mises, L. (2007). La acción humana. Tratado de economía, Unión Editorial Madrid, 8. ${ }^{\mathrm{a}}$ Edición.

Nicholson, W. (2003). Teoría microeconómica: Principios básicos y aplicaciones, McGrawHill, España, 6. ㄹ Edición.

RADFORD, R.A. (1945). «The economic organization of a P.O.W. camp», en Economica, Noviembre 1945, Vol. 12. pp. 189-201. 